\title{
Appeal of $3+4$ Program: Good Students are Few but Growing at Secondary Vocational Schools in Shanghai
}

\author{
XU Hui \\ Shanghai University of Engineering Science, Shanghai, China \\ Shanghai Gaoji Jigong School, Shanghai, China \\ XIE Peng-yang \\ Shanghai Business School, Shanghai, China
}

\begin{abstract}
Secondary vocational education in Shanghai continues to experiment in an attempt to find ways to solve the decline of student enrollment and adjust to rapidly changing social and economic environments. The $3+4$ Pilot Program (three-year secondary vocational education and four-year undergraduate education) has been under experiment since 2014. It has attracted more and more academically good junior middle school graduates to secondary vocational schools with the national and local favorable policies and laws. Except the three-year's hand-on practice, what appeals most to the junior middle school graduates is the academic transfer under the Program, a breakthrough in history of vocation education in China. However, only initiating a new program is not enough. Shanghai government should map out a long-term plan to set up promotion to increase the public awareness to change the long prevailing outdated ideology in order to add more to its appeal of the Program. There is still much work to be done before expanding the scope of the Program.
\end{abstract}

Keywords: appeal, Pilot Program, student enrollment, secondary vocational schools

\section{Introduction}

In Shanghai, as in any other city in China, secondary vocational education generally refers to the secondary level vocational school system consisting of three forms of vocational institutions, namely, "Zhongzhuan" schools (the specialized secondary schools), "Jigong" schools (the technical schools or the schools for the skilled workers), and "Zhigao" schools (the vocational senior middle schools/vocational high schools). These three schools primarily enroll junior middle school graduates. The duration for the "sanxiao sheng" (three-school students) is generally three or four years. For a long time, the three-school secondary vocational education had trained middle-level factory workers and middle-level cadres with specialized skills and had been successful for the assignment of work upon the graduation by the state especially before the 1990s.

However, with the development of the market-dominated society, some state-owned enterprises went bankrupt while more and more collectives and private enterprises flooded in. As a result, fewer and fewer jobs

XU Hui, M.A., associate professor, Vocational College, Shanghai University of Engineering Science, Shanghai, China; Shanghai Gaoji Jigong School, Shanghai, China.

XIE Peng-yang, Ph. D., lecturer, Department of Economic Statistic, Shanghai Business School, Shanghai, China. 
were offered to the "sanxiao sheng" by the state-owned enterprises upon they graduated. On the other hand, for the collectives and private enterprises especially those in big cities, for some vacancies, there were no enough qualified skilled labor applicants, while the three-year vocational education they had received did not improve the graduates' employment opportunities. Thus, the resulting declines in enrollment at the end of the 20th century were not surprising. Ministry of Education of China has initiated a series of measures, with the aim of reversing its decline and addressing a shortage of skilled workers to better meet demand in the market and increase employment. One of the measures is to introduce channels to transfer to academic education to obtain degrees at universities, after training application-oriented students with all round quality directly engaged in the forefront of production, technology, and service in secondary vocational schools.

\section{Literature Review}

Throughout the history of vocational education in China, "sanxiao sheng" would hardly get the chance to transfer to universities. In the early 1960s, the double-track education system-"walking on two legs" officially argued that academic and vocational were parallel and are not transferable ${ }^{1}$. From then on, vocational education hardly had anything to do with the academic education. In other words, once in the vocational education track, chances for higher education were very slim. Vocational education became an endpoint of a student's education. As a result, only those students who failed to pass the "zhongkao" (the High School Entrance Exam) and could not go to a "putong gaozhong" (a regular senior high school which offers chances to take the Nation Entrance Examination to go to universities) had to choose secondary vocational schools.

Based on an ethnographic fieldwork conducted in 2007-2012, Mette Halskov Hansen and T. E. Woronov (2013, pp. 242-259) stated:

Parents and students had deeply-held objections to vocational education in China. In urban cities, vocational education have long held lower status than academic education, and even parents today are unlikely to prefer vocational education if their child has any option at all of getting into a putong gaozhong.

It has been held in their paper that secondary vocational studies are mostly chosen as a last resort, rather than by personal or family interest. Using a random sampled baseline survey and follow-up survey of 2,216 second-year students residing outside of county seats in 41 impoverished counties in China, Yingquan Song, Prashant Loyalka, and Jianguo Wei (2013, pp. 30-42) found that "the path of vocational high school (a Zhigao school) is not preferred by rural junior middle school students. Most students will select academic high schools (putong gaozhong) over vocational high schools (Zhigao schools). Minhua Ling (2015, pp. 108-131) also argued that in China only "bad students go to secondary vocational schools".

Recently, however, under new programs, some good students really have been enrolled to "sanxiao" schools (Zhongzhuan schools, Jigong schools, and Zhigao schools) especially in some larger cities in China, such as Shanghai. Perhaps because new programs are being under experiment, to date, outside of China, few studies have looked at the new change of the secondary vocational education, and fewer still found the appeal of the $3+4$ Program of "sanxiao" schools in Shanghai.

In the paper, the definition of the $3+4$ Program is given followed by introduction of the dramatic increase of student enrollment from 2014-2018. Then what appeals to the junior middle school graduates will be discussed. Finally, a few policy recommendations are put forward to appeal more students to secondary

${ }^{1}$ Vocation education in China. Retrieved July, 11, 2014, from https://en.wikipedia.org/wiki/Education_in_China 
vocational education. The goal of the paper is therefore to provide insight on the $3+4$ Program in order to understand the appeal of the secondary vocational education for those who are interested in it.

\section{The $3+4$ Program}

China's government has been taking some measures to enhance vocational education in the country, calling for improvements to better meet demand in the market and increase employment. Aiming to accelerate the reform and development of vocational education system, The China Vocational Education Law of 1996 regulated that "vocational education is an important path to promoting economy, improving society, and assuring employment" ${ }^{2}$. The Outline of National Plan for Medium-and-Long-Term Educational Reform and Development (2010-2020) ${ }^{3}$ in 2010, and The Decision on Accelerating the Development of Modern Vocational Education" in 2014, both issued by the State Council of the People's Republic of China (PRC), pointed out the importance of promoting the communication between vocational education and academic education, hence to build a pathway for the students to transfer from vocational education to academic education. Thereafter, a number of local laws and regulations have been developed in cities, like Shanghai. To cater to the employment market's need for skilled workers, Notice on the Pilot Program of Articulation Education of Secondary Vocational Schools and Application-oriented Undergraduate Institutions (the Notice) issued in 2014 by Shanghai Municipal Education Commission laid a foundation for the articulation of two kinds of parallel education: vocational and academic. ${ }^{5}$

The Pilot Program is in a $3+4$ fashion (three-year secondary vocational education and four-year undergraduate education). Students enrolled under the Program have to not only sit in class to grasp the basic culture knowledge, such as English, Math, and Chinese, but also grasp their specialty knowledge and skills. Besides, they should do some professional practice outside the classroom. The duration is three years in one of the "sanxiao" schools. Then, they will continue to study for four years in universities. However, before transferring to an academic university they will need to take transfer examination held in May each year. The transfer examination is composed of two parts: One is entrance examination of the basic knowledge held by Shanghai Municipal Educational Examinations Authority. To pass it, students must be good at English, Math, and Chinese. The other is the entrance examination of specialty held by the participant schools or universities. In order to pass this examination of their specialty, they must do well in their specialty studies and be perfect in hand-on practice.

Though it is not easy to transfer from one of the "sanxiao" schools to a participant college or university, the $3+4$ Program really attracts more and more academically good students. Great changes in enrollment of secondary vocational education have taken place in participant "sanxiao" schools in Shanghai.

\footnotetext{
2 The China Vocational Education Law. Retrieved July, 17, 2018, from http://www.moe.gov.cn/s78/A02/zfs__left/s5911/moe_619/tnull_1312.html?authkey=yx9zv2

3 Outline of National Medium-and-Long-Term Educational Reform and Development Plan (2010-2020). Retrieved July,17, 2018, from http://old.moe.gov.cn/publicfiles/business/htmlfiles/moe/info_list/201407/xxgk_171904.html

${ }_{4}$ The Decision on Accelerating the Development of Modern Vocational Education by the State Council. Retrieved July, 17, 2018, from http://www.moe.edu.cn/jyb_xxgk/moe_1777/moe_1778/tnull_27730.html

${ }_{5}$ Notice on the Pilot Program of Articulation Education of Secondary Vocational Schools and Application-oriented Undergraduate Institutions. Retrieved July,17, 2018, from http://www.seei.edu.sh.cn/Default.aspx?tabid=133\&ctl=Details\&mid=556\&ItemID=2227\&SkinSrc=[L]Skins/jypgy_1fen/jypgy_ 1 fen
} 


\section{Appeal of the New Program: Sharp Increase in Student Recruitment}

From the 1970s to 1990s, Shanghai built up a vocational education system, mainly made up of "sanxiao" schools. However, from late the 1990s, the development of Shanghai's vocational education lagged behind the requirements of the city's industrial transformation, from manufacturing to financial and other high-end sectors. Even worse, the lack of adaptability and chances for further education hindered the upgrading of Shanghai's vocational education system. Shortly, after the notice and other policies were issued, a few "sanxiao" schools in Shanghai were on the way to experimenting with the new program-the " $3+4$ " Pilot Program. In 2014, three "sanxiao" schools and two universities were selected for the Pilot Program, and 120 junior middle school graduates were planned to be enrolled that year. In 2015, the Program was well received and the enrollment number increased to 630, up more than 400 percent from the year before. In 2018, the number increased dramatically to 1,730 . In 2014 , only two universities and three "sanxiao" schools implemented the $3+4$ Program, while in 2018, 14 universities and 37 "sanxiao" schools did. In Shanghai, there are about 35 colleges or universities and 85 "sanxiao" schools in total. Except the elite universities of Project 985 or Project 211, all the application-oriented institutions funded by local government and all the key "sanxiao" schools were the participants in 2018. Meanwhile, more and more hot majors have been added to the curricula to meet the demand from applicants. Only within the last four years, the number of majors had increased from two in 2014 to 51 in 2018. To sum up, the number of participant universities, "sanxiao" schools, student enrollment or specialties in 2018 was about 10 times more than that in 2014 (see Table 1).

Table 1

The Student Enrollment of the Sanxiao Schools in Shanghai (2014-2018)

\begin{tabular}{llllll}
\hline Year & 2014 & 2015 & 2016 & 2017 & 2018 \\
\hline Number of students to be enrolled & 120 & 630 & 970 & 1611 & 1730 \\
Number of admission specialties & 2 & 14 & 25 & 37 & 51 \\
Number of the participant sanxiao schools & 3 & 16 & 22 & 32 & 37 \\
Number of participant universities & 2 & 12 & 11 & 12 & 14 \\
\hline
\end{tabular}

Note. Source: Data collected from Shanghai Municipal Educational Examinations Authority.

Shanghai has made remarkable progress not only in the quantity but also in the quality of student enrollment. Table 2 shows there is a tendency for the academically good students to go to "sanxiao" schools. In 2014, the lowest score for the actual admission to "sanxiao" schools was 510.0, five marks higher than that for the putong gaozhong schools. In 2015, the lowest score for the actual admission to "sanxiao" schools was 475.0, 19.5 marks higher than that for putong gaozhong schools. Either in 2017 or in 2018, the lowest score for the actual admission to "sanxiao" schools was more than 40 marks higher than that for the admission to the putong gaozhong schools. Although the academically best students still chose "shi zhongdian" schools (Shanghai city's key putong gaozhong schools), more and more students who got the required scores for "qu zhongdian" schools (Shanghai 16 district's key putong gaozhong schools, which are not so good as shi zhongdian), chose to enter "sanxiao" schools under $3+4$ Pilot Program instead, which was really rare in history of vocational education. In contrast, the highest scores for the admission to "sanxiao" schools which were not under the $3+4$ Program were more or less the same within the past five years. 
Table 2

Scores of the Student Admission to Sanxiao Schools in Shanghai (2014-2018)

\begin{tabular}{llllll}
\hline Year & 2014 & 2015 & 2016 & 2017 & 2018 \\
\hline The lowest score for the admission to sanxiao schools & 510.0 & 475.0 & 495.0 & 502.5 & 450.50 \\
The lowest score for the admission to putong gaozhong schools & 495 & 455.5 & 475 & 457 & 406 \\
The highest score for the admission to sanxiao schools & 350 & 320 & 350 & 335 & 315 \\
\hline
\end{tabular}

Note. Source: Data collected from Shanghai Municipal Educational Examinations Authority.

\section{Discussion and Recommendation}

Compared with the large number of the rest of "sanxiao sheng", the academically good students who choose "sanxiao" schools under the program are still few, but are growing dramatically over the past five years. Shanghai has been successful in experimenting with this new type of vocational schooling. The three years' study at a "sanxiao" school prepares students with practical skills and will be bound to improve their employment opportunities for their future careers. What appeals most to the junior middle school graduates is that the secondary vocational education under the Program does not indicate an end in education as it is in Germany, though vocational education of China has been greatly influenced by Germany for a long time. "Sanxiao sheng" can choose to go on taking undergraduate courses and gain bachelor's degrees instead of immediately entering the job market. Besides, upon graduating from universities, these students can get not only bachelor's degrees, but also profession certificates. Besides, it has been predicted by some educational experts that these graduates can choose to go on taking graduate courses and gain vocational master's degrees, and even vocational doctor's degrees in the future. A pathway is being built for vocational students to transfer to academic education, which is a great breakthrough of vocational education in China ( $\mathrm{Xu}, 2017)$.

Education research in China has largely focused on the academic stream (Goodman, Hatakenaka, \& Kim, 2011), and has tended to overlook the influence of popular attitudes and social ideology on the current system of secondary vocational education. For vocational education to become an attractive and desirable option for junior middle school graduates, Shanghai Municipal Education Commission will need to do more than experiment a new program; it will need the public to thoroughly change attitudes and ideologies towards secondary vocational education. In contemporary China, the old concept "a good scholar can become an official" is still deeply rooted and cannot be changed overnight while "skills are respected and labor is noble" has not been well passed on yet. Being a technical specialist and working with one's hands are not the ideals sought (Schmidtke \& Chen, 2012). Vocational skills are still considered to be taught to lower-class children. In other words, vocational qualification holders do not receive much recognition and respect, instead they are placed a notch below university graduates in China. In contrast, in some developed counties where vocational education develop very rapidly, such as UK, Germany, and the United States, vocational education graduates are highly respected for their skills. To meet the demands of the rapid development of society in Shanghai, the attitude and ideology is a must to change.

It is argued in China Daily that:

The increase of student number does not mean the vocational education has won society's recognition. The discriminative attitude towards manual labors imbedded in Chinese culture makes it hard to change the stereotype image of vocational education that only the wooden-headed and poor children go to technical schools. (Yang, 2014, p. 6) 
To change attitudes and social ideology is a long-term process. Fundamentally changing the traditional disdain in Shanghai for secondary vocational education needs to reform personnel system and change hiring mechanisms in companies. Government at all levels should strengthen publicity efforts for secondary vocational education, and create a favorable public opinion atmosphere for the development of secondary vocational education (Liu \& Chen, 2013).

\section{Conclusion}

China now is in the springtime of vocational education (Wang \& Jiang, 2013). The past five years saw the dramatic increase in the student enrollment under the $3+4$ Pilot Program though the number of the students was still few but growing rapidly. In the first three years in "sanxiao" schools, the students were trained with specified qualifications suitable for specific jobs. What appeals most to the junior middle students is the university transfer, a giant leap in China education history. However, only initiating a few new programs is far from enough to serve the fast changing society. Some old ideologies about vocational education prevailing for a long time could not be changed overnight, which will inevitably be the barrier to the rapid development of the vocational education. That is why the Shanghai educational authorities are taking an observe-while-walking attitude towards expanding the student enrollment of this Pilot Program. They do not want to interrupt or shatter the academic dreams of the "sanxiao sheng". The China government will need to map out a long-term plan to increase public awareness, create a public opinion atmosphere much more favorable to vocational education. Only in this way, to some extent, can the reform of secondary vocational education achieve its goal.

\section{References}

Goodman, R., Hatakenaka, S., \& Kim, T. (2011). The Changing status of vocational higher education in contemporary Japan and the Republic of Korea. UNESCO-UNEVOC Discussion Paper Series 4, UNEVOC International Centre for Technical and Vocational Education and Training.

Hansen, M. H., \& Woronov, T. E. (2013). Demanding and resisting vocational education: A comparative study of schools in rural and urban China. Comparative Education, 49(2), 242-259.

Ling, M. H. (2015). Bad Students Go to Vocational Schools! Education, social reproduction and migrant youth in urban China. The China Journal, 73, 108-131. doi: 10.1086/679271

Liu, J., \& Chen, G. F. (2013). Reflections on developing secondary vocational education in high-poverty areas. Chinese Education and Society, 46(4), 68-74.

Schmidtke, C., \& Chen, P. (2012). Philosophy of vocational education in China: A historical overview. Journal of Philosophy of Education, 46(3), 432-448.

Song, Y. Q., Loyalka, P., \& Wei, J. G. (2013). Determinants of tracking intentions, and actual education choices among junior high school students in rural China-Evidence from forty-one impoverished western counties. Chinese Education and Society, 46(4), 30-42.

Wang, L., \& Jiang, D. Y. (2013). Chinese vocational education: Borrowing and reforming-An interview with Professor Dayuan Jiang, MOE research fellow. Chinese Education and Society, 46(4), 92-99.

$\mathrm{Xu}, \mathrm{H}$. (2017). A comparative analysis of academic transfer of Sino-US vocational education. The 4th International Conference on Advanced Education and Management (ICAEM 2017), December16-17, Qingdao, China. ISBN: 978-1-60595-519-3

Yang, L. (2014). Upgrade schools to raise image of graduates. China Daily, 07/11/2014, p. 6. 